\title{
Evolution and classification of Mesozoic mathildoid gastropods
}

\author{
Joachim Gründel and Alexander Nützel \\ Acta Palaeontologica Polonica 58 (4), 2013: 803-826 doi: http://dx.doi.org/10.4202/app.2012.0052
}

\begin{abstract}
About 150 Mesozoic (mostly Early and Middle Jurassic) species of the heterobranch superfamily Mathildoidea are classified into four families and 27 genera. Most taxa are assigned to the families Mathildidae, Gordenellidae, and Tofanellidae while the Triassic family Anoptychiidae holds only a single genus and is restricted to the Late Triassic. Mathilda janeti is designated as type species for the genus Promathildia. Earlier designations are invalid because they refer to species which were not originally included in the genus Promathildia. As a consequence, Promathildia is transferred from Mathildidae to Gordenellidae. The generic assignment of numerous mathildoid species is changed. The suggested classification represents an arrangement which is based on shell characters; it is not based on a cladistic phylogenetic analysis.However, a great number of fossil taxa can only be classified based on shell characters. A high mathildoid diversity has been recognized from the Late Triassic Cassian Formation. Many of these taxa are unknown form the Jurassic and probably became extinct during the end-Triassic mass extinction event. However, at least five genera (probably eight) survived the end-Triassic mass extinction event. Tricarilda, Jurilda, and Promathildia are rather conservative, long ranging groups of high Jurassic species diversity. They probably gave rise to the modern Mathildidae. One new genus is described: Angulathilda gen. nov.
\end{abstract}

Key words: Gastropoda, Heterobranchia, Mathildoidea, classification, Triassic, Jurassic, end-Triassic mass extinction event.

Joachim Gründel [joachim.gruendel@lingua-pura.de], Institut für Geologische Wissenschaften, Fachbereich Paläontologie, Freie Universität Berlin, Malteserstraße 74-100, Haus D, 12249 Berlin, Germany; Alexander Nützel [a.nuetzel@1rz.uni-muenchen.de], Bayerische Staatssammlung für Paläontologie und Geologie, Ludwig-Maximilians-University Munich, Department für Geound Umweltwissenschaften, Sektion für Paläontologie, Geobio-CenterLMU, Richard Wagner Str. 10, 80333 München, Germany. 
This is an open-access article distributed under the terms of the Creative Commons

Attribution License (for details please see creativecommons.org), which permits unrestricted use, distribution, and reproduction in any medium, provided the original author and source are credited.

For Full text $(1,004.3 \mathrm{kB})$ 